\title{
OLEKSANDR ANDRIIOVYCH BOICHUK (ON HIS 65TH BIRTHDAY)
}

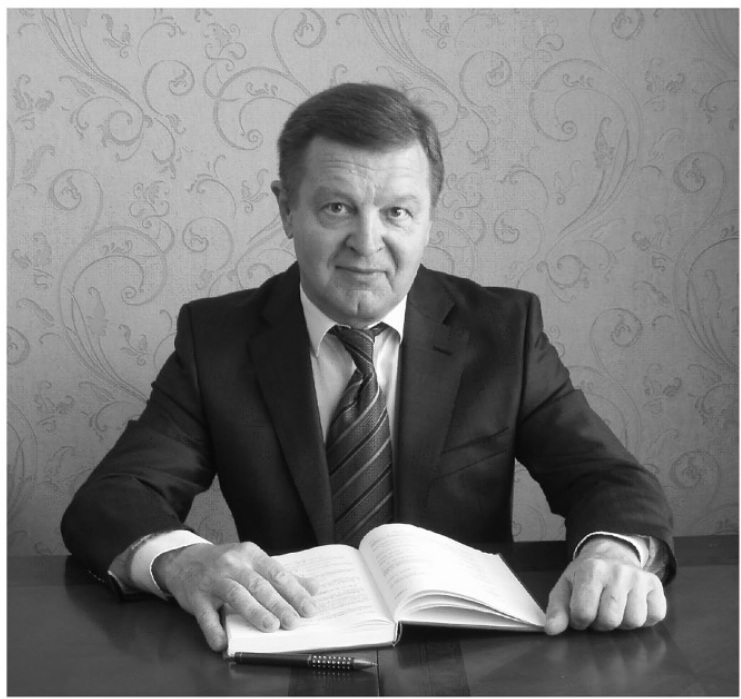

June 30, 2015 marked the 65th birthday of Oleksandr Andriiovych Boichuk, prominent scientist, Corresponding Member of the Ukrainian Academy of Sciences, Winner of the Ukrainian State Prize in the Field of Science and Technique.

O. A. Boichuk was born on June 30, 1950, in Kirovograd. In 1967, he graduated from the Kirovograd secondary school No. 11 and entered the Department of Mechanics and Mathematics of the Shevchenko Kyiv State University. After graduating from the postgraduate courses at the Institute of Mathematics of the Ukrainian Academy of Sciences, he defended his candidate-degree thesis in 1978 and the doctoral-degree thesis in 1992. Since 1994, he headed the Laboratory of Boundary-Value Problems at the Institute of Mathematics. In 1997, he was given the academic status of professor in the field of "differential equations."

Prof. Boichuk is a prominent expert in the theory of resonance boundary-value problems with normally solvable operator in the linear part. He established the conditions of solvability for a broad class of nonlinear boundaryvalue problems for systems of ordinary differential and difference equations, equations with delayed argument, equations with impulsive action, integrodifferential equations, and singularly perturbed equations. To study these problems, he proposed and extensively used the theory of generalized inverse operators. This enabled him to significantly develop the qualitative theory of boundary-value problems for these systems. For the first time, he obtained numerous original results for boundary-value problems with conditions imposed at infinity. He established criteria for the existence of solutions bounded on the entire axis for linear and nonlinear systems of ordinary differential and difference equations under the assumption of exponential dichotomy of the linearized homogeneous system on

Institute of Mathematics, Ukrainian National Academy of Sciences, Ukraine, 01601, Kyiv, Tereshchenkivs'ka Str., 3

Translated from Neliniini Kolyvannya, Vol. 18, No. 2, pp. 147-148, April-June, 2015. 
semiaxes and proposed algorithms for the construction of these solutions. He also derived conditions of bifurcation and branching for the solutions of the indicated class of problems. His results develop the well-known results of the Kyiv Mathematical School in the theory of nonlinear oscillations founded by the famous scientists N. M. Krylov and N. N. Bogolyubov. Prof. Boichuk is the author of more than 150 works and 3 monographs. His monograph written together with his teacher and college, Academician A. M. Samoilenko was published in English in the Netherlands and in the USA. His textbook in the theory of boundary-value problems for students of universities was published in Slovakian language in Slovakia.

His scientific results are well known for experts and were delivered by him at numerous leading international conferences in Austria, Belgium, Bulgaria, Great Britain, Greece, Israel, Spain, Latvia, Germany, Poland, Romania, Slovakia, Hungary, Czechia, and in most countries of the former USSR, where he was often a member of the Organizing Committees and/or invited speaker. He received grants of NATO (Science Fellowships Programme 2002-2003), Slovak and Czech Grant Agencies (2003-2010), and the Ukrainian State Foundation for Fundamental Research (1995-2012).

For last twenty years, O. A. Boichuk combines his research activities with working as Professor of the Chair of Integral and Differential Equations at the Shevchenko Kyiv National University. He also occupied the position of professor-researcher (2002-2010) at the Žilina University (Slovakia). Among his disciples, there are one doctor and 12 candidates of sciences (including one $\mathrm{PhD}$ thesis in Slovakia). He was awarded the prestige Mitropol'skii Prize of the Ukrainian National Academy of Sciences. For a long period of time, he is a member of the profile council for the defense of doctoral-degree theses at the Shevchenko Kyiv National University. Prof. Boichuk is also Deputy Editor-In-Chief of the "Nonlinear Oscillations" journal and a member of the editorial board of the "Bukovyns'kyi Matematychnyi Zhurnal." The full list of publications of Boichuk can be found at the sites of the Institute of Mathematics of the Ukrainian National Academy of Sciences (http://imath.kiev.ua) and Google Scholar Citations (http://scholar. google.com).

Oleksand Andriiovych Boichuk is full of creative scientific ideas and energy for their realization. We wish him good health and new successes in his creative activities for the welfare of Ukraine.

A. M. Samoilenko, I. T. Kiguradze, I. O. Lukovs'kyi, V. L. Makarov, M. O. Perestyuk, O. M. Sharkovs'kyi, I. Diblik, V. P. Zhuravl'ov, M. Medved', I. O. Parasyuk, M. Kh. Rozov, O. M. Stanzhyts'kyi, Yu. V. Teplins'kyi, V. I. Tkachenko, and M. Fečkan 